\title{
Simulation Analysis on Flow Field and Temperature Field in Mould of Special Thick Slab Caster
}

\author{
Bao YANG, Jing LI, Lian-wang ZHANG, Yu ZHANG, Ye CUI, Chang-jun XU
}

\begin{abstract}
A three-dimensional model of the thick slab continuous casting mould of $400 \times 2200 \mathrm{~mm}$ was established. The effects of immersion depth of nozzle and casting speed on the flow field and temperature field were investigated. The high temperature distribution in mould, the thickness of narrow face solidified shell, the impact position of stream and the free surface velocity were used as the main points of analysis. Simulation and practical water modelling both exhibited the same changing trends, namely, the flow velocity of the surface increases with the distance from nozzle. The scientific basis for optimizing the flow field and temperature field in the continuous casting of special thick slab mould was acquired through calculations.
\end{abstract}

Keywords: flow field; numerical simulation; special thick slab; temperature field

\section{INTRODUCTION}

With the rapid development of nuclear power steel, ship plate steel for the military, low welding cracksensitive high-strength steel, and the steel of special pressure vessels, a growing demand for thick slab has risen. It is generally known that the continuous casting slab is the main source of the production of special thick slab. Meanwhile, the mould is the most important component in the continuous caster and the last step to control the purity of molten steel. The hot metal flows and heat transfer in the mould are attracting increasing attention from researchers $[1,2]$. A common way to optimize such processes is via experimentation; however, the experimental time period for the relevant experiments is long and the monetary cost is high. On the contrary, one can avoid those experimental drawbacks via numerical simulation [3]. Therefore, the mathematical model that describes the flow and heat transfer in mould was established. Based on the model, a series of studies with computerized simulation were conducted, and finally, the results were used to guide actual production.

In recent years, a large number of numerical simulation studies have been done on the flow field and temperature field in the mould. Mills et al. [4] showed that the centre of the narrow face shell at the mould outlet is the thinnest and increases from the centre to both sides gradually. The growth of the wide face solidification shell is influenced faintly by stream impact; hence, it is more uniform than a narrow face. When researching the flow field and the temperature field under the different immersion depths of nozzle conditions by simulations, Thomas et al. [5] found that, the fluctuation of free surface was not obvious when the nozzle immersion depth changed between 130 and $170 \mathrm{~mm}$. In addition, Zhu et al. [6], Saraswat et al. [7] also used numerical simulations to conduct research on the flow field and temperature field in the mould.

The continuous casting mould is not only the beginning of the molten steel solidification, but also the last filter [8]. The flow of molten steel and the solidified heat transfer are two basic physical phenomena in the mould. In the current study, fluid flow behaviour and temperature field effects in continuous casting of special thick slab mould were numerically simulated.

\section{MATHEMATICAL MODEL 2.1 Assumptions}

In the model, the molten steel is assumed to be an incompressible fluid with a steady flow, and it is a continuous medium with constant temperature [9]. The effect of oscillation, taper, and solidified shell on the flow was ignored. The zone of molten steel over $1,770 \mathrm{~K}$ is referred to as the high temperature zone.

\subsection{Governing Equations}

The effect of steel solidification on flow and heat transfer is considered herein. The flow of molten steel in the mould is described as a steady state and was not a turbulent fluid flow. Therefore, the model is in accord with the continuity equation, $N-S$ equation, $k-\varepsilon$ model equation and energy equation [5].

\subsection{Boundary Conditions}

The initial temperature in the mould is room temperature $\left(25^{\circ} \mathrm{C}\right)$. The starting point of the liquid steel is static, and the velocity is $0 \mathrm{~m} / \mathrm{s}$. The velocity inlet described the nozzle inlet. The volume fraction of the steel liquid is $100 \%$ at the entrance. The position of the flow field outlet is in the bottom of the mould. The longitudinal gradient of various physical quantities is set to zero on the symmetric surface of the centre surface in the mould. The distance is $100 \mathrm{~mm}$ from the upper surface of the molten steel to the top of the mould, and the molten steel in the mould is covered by a layer of $30 \mathrm{~mm}$ flux. The upper surface of mould flux is regarded as air, and the upper surface of the air zone is a symmetry plane.

\subsection{Special Thick Slab Caster Description}

The object of study is a mould designed for the continuous casting of thick slab intended for special thick slab, as shown in Fig. 1. Numerous parameters for the steel have been given, as shown in Tab. 1. Tab. 2 lists parameters of the special thick slab mould in this study. In the experiment, according to the principle of similarity theory, in terms of model of 1:0.55, we use water instead of liquid steel to study fluid flow in mould. 
Table 1 Parameters applied in the mathematical model

\begin{tabular}{|l|c|}
\hline \multicolumn{1}{|c|}{ Parameters } & Values \\
\hline Density $/ \mathrm{kg} \cdot \mathrm{m}^{-3}$ & 7020 \\
\hline Solidus temperature $/{ }^{\circ} \mathrm{C}$ & 1334 \\
\hline Liquidus temperature $/{ }^{\circ} \mathrm{C}$ & 1494 \\
\hline Viscosity of molten metals $/ \mathrm{Pa} \cdot \mathrm{s}$ & 0,0062 \\
\hline Specific heat $/ \mathrm{J} \cdot(\mathrm{kg} \cdot \mathrm{K})^{-1}$ & 698 \\
\hline Thermal conductivity of molten metals $/ \mathrm{W} \cdot(\mathrm{m} \cdot \mathrm{K})^{-1}$ & 26 \\
\hline Thermal conductivity of metals $/ \mathrm{W} \cdot(\mathrm{m} \cdot \mathrm{K})^{-1}$ & 31 \\
\hline Latent heat $/ \mathrm{J} \cdot \mathrm{kg}^{-1}$ & 268000 \\
\hline
\end{tabular}

Table 2 Parameters of special thick slab mould

\begin{tabular}{|l|c|}
\hline \multicolumn{1}{|c|}{ Parameters } & Values \\
\hline Mold width $/ \mathrm{mm}$ & 2200 \\
\hline Mold length $/ \mathrm{mm}$ & 800 \\
\hline Mold thickness $/ \mathrm{mm}$ & 400 \\
\hline Casting speed $/ \mathrm{mm} \cdot \mathrm{min}^{-1}$ & $0,30,50,7$ \\
\hline Immersion depth of nozzle $/ \mathrm{mm}$ & 120140160 \\
\hline
\end{tabular}

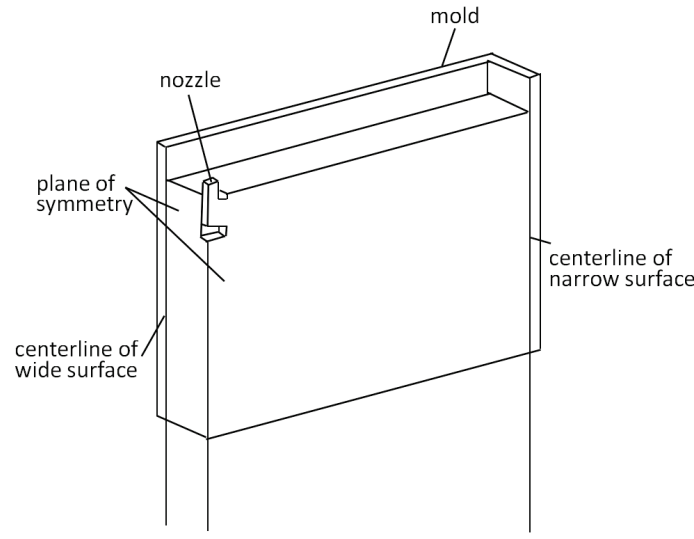

Figure 1 The geometrical model of mould

\section{MODEL VERIFICATION AND SIMULATED RESULTS \\ 3.1 Model Verification}

The changing of the temperature field depends upon the flow field in the mould, nevertheless, the shape of flow field is determined by the velocity of molten steel. According to the literature, the maximum surface velocity of the mould is located in the width direction and within the distance range of $1 / 8$ to $1 / 4$ from the narrow surface [10]. Therefore, in the water modelling, the positions of $1 / 8(\mathrm{~A}), 3 / 16(\mathrm{~B})$, and $1 / 4(\mathrm{C})$ at the mould section were selected as surface velocity measurement points, as shown in Fig. 2.

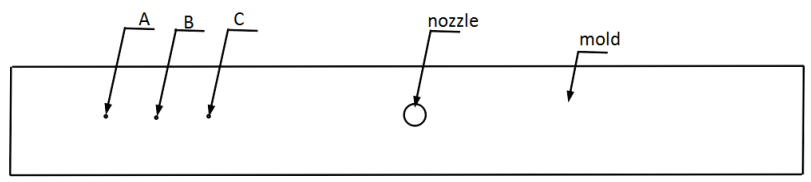

Figure 2 The measurement point of surface velocity

Based on the continuous casting process parameters, the experimental and simulation results of surface flow velocity are shown in Fig. 3. The surface flow velocity would increase with distance from the nozzle. As the distance is $0.2 \mathrm{~m}$, experimental results show that the flow velocity of the surface is $0.078 \mathrm{~m} / \mathrm{s}$, and the simulation result is $0.08 \mathrm{~m} / \mathrm{s}$; the experimental and theoretical results are in good agreement. The results indicate that the results of the simulations coincide well with the experiment. This indicates that the temperature field and flow field obtained by this model are accurate.

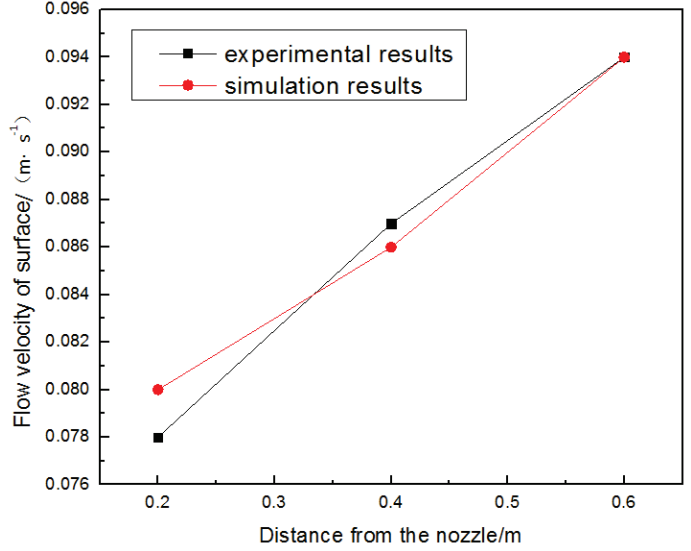

Figure 3 Comparison between the simulation and experimental results

\subsection{Effects of the Depth of Nozzle}

The immersion depth of the nozzle has no overall effect on the flow of molten steel in the mould, but it has a great effect on the free surface fluctuation and jet impingement on the narrow surface.

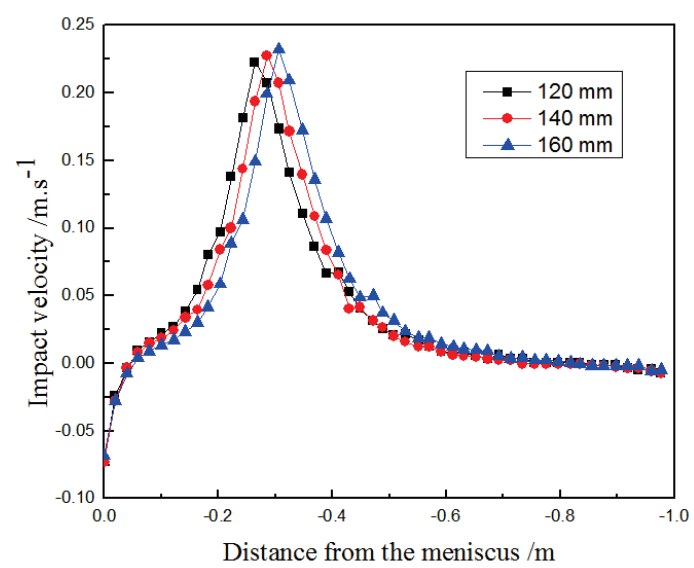

Figure 4 The velocity distribution of the narrow surface impact in the mould

Fig. 4 shows the velocity distribution of the narrow surface under different immersion depths. It can be seen from the figure that the impact velocity is close to $0 \mathrm{~m} / \mathrm{s}$ at the meniscus. At about $0.3 \mathrm{~m}$ below the meniscus, both the velocity of different immersion depths reach the maximum value of about $0.3 \mathrm{~m} / \mathrm{s}$. As the immersion depth of nozzle was increased from $120 \mathrm{~mm}$ to $160 \mathrm{~mm}$, the impact position of the stream in the flow field decreased slightly, but no significant changes were obvious. In addition, with the increase of the immersion depth of the nozzle, the velocity at the impact position of stream on the middle line of the narrow surface increases slowly. The depth of the impact point has negative effects on inclusion flotation, bubble distribution, shell growth, and so on. If the impacting position is near the mould outlet, there is no guarantee that the solidification shell at the mould outlet will reach the safe thickness, which is not conducive to safe production.

As can be seen from Fig. 5, the velocity decreases from $0.3 \mathrm{~m} / \mathrm{s}$ to $0.2 \mathrm{~m} / \mathrm{s}$ at wide surface increases with the immersion depth of the nozzle. In the meantime, the upper recirculation zone becomes larger when the immersion depth is deepened; this resulted in a smaller velocity at the liquid surface. The velocity is as high as 
$0.3 \mathrm{~m} / \mathrm{s}$, which is the critical velocity of flux of the liquid surface when the immersion depth is $120 \mathrm{~mm}$ [11]. This can easily expose the surface of the liquid. At the same time, it can be seen that when the immersion depth is greater than $140 \mathrm{~mm}$, the effect of the depth change on the liquid surface velocity becomes very small (see Fig. $5)$. From the above analysis, in view of the thick slab continuous casting process, to guarantee that the surface velocity is lower than the critical velocity of flux, one should choose a shallow immersion depth. Increasing the fluctuation and temperature on the surface of molten metal are good options for inclusion flotation and slag melting.

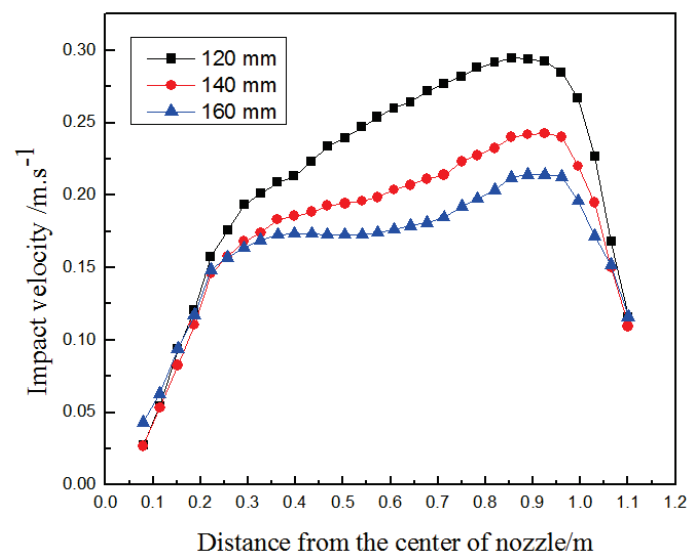

Figure $\mathbf{5}$ The distribution of flow velocity in the broadside at the mould meniscus

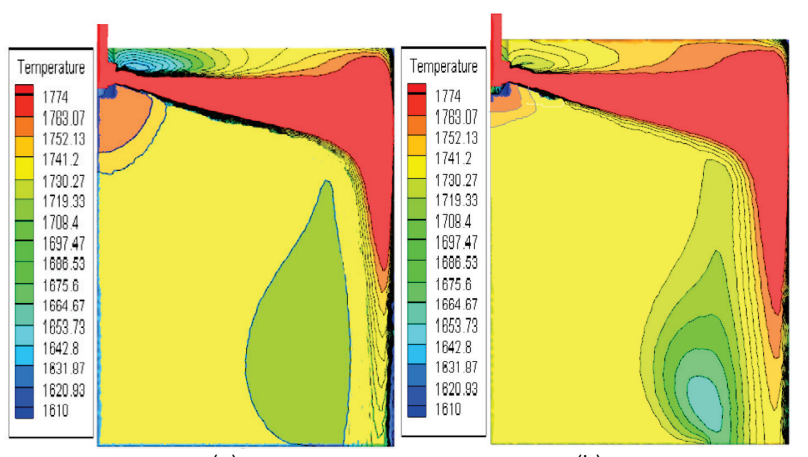

(a)

(b)

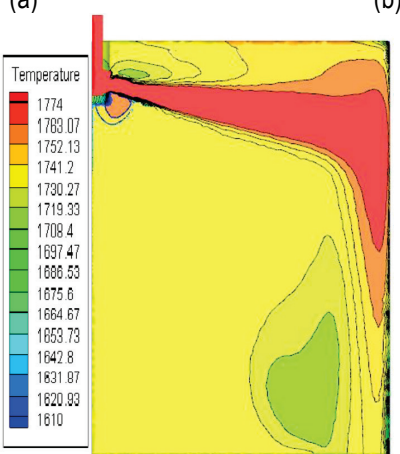

(c)

Figure 6 Distribution of wide surface temperature field at different depths: (a) A depth of $120 \mathrm{~mm}$; (b) A depth of $140 \mathrm{~mm}$; (c) A depth of $160 \mathrm{~mm}$

The temperature field is given in Fig. 6. It can be observed that the upper recirculation zone increases and the lower recirculation zone decreases. This occurs slowly when the immersion depth increases. The high temperature zone decreases with the augment of the upper recirculation zone; however, it is not obvious at the lower recirculation zone with the augmentation of the immersion depth. The results show that the high temperature zone moved down with increasing immersion depth of nozzle. When the immersion depth exceeds $140 \mathrm{~mm}$, it is not conducive to slag melting, thus it cannot remove the inclusion in the molten steel. Therefore, the best immersion depth of the nozzle is 140 $\mathrm{mm}$ in this study.

\subsection{Effects of Casting Speed}

It is known from the previous conclusions that the temperature field and flow field are reasonable when the immersion depth of nozzle is $140 \mathrm{~mm}$. In order to optimize the liquid steel flow field and temperature field, the casting speed was investigated under the condition in the $140 \mathrm{~mm}$ immersion depth.

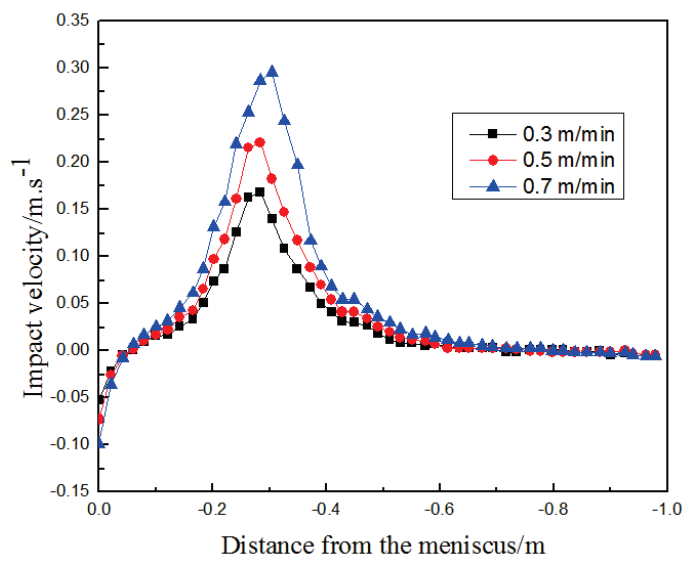

Figure 7 The velocity distribution of the narrow surface impact in the mould

It can be seen from Fig. 7 that the impact velocity of narrow surface increases from $0.17 \mathrm{~m} / \mathrm{s}$ to $0.3 \mathrm{~m} / \mathrm{s}$ when the casting speed increases and that the impact position of the stream is unchanged. Therefore, it has less influence on the impact position change of the stream.

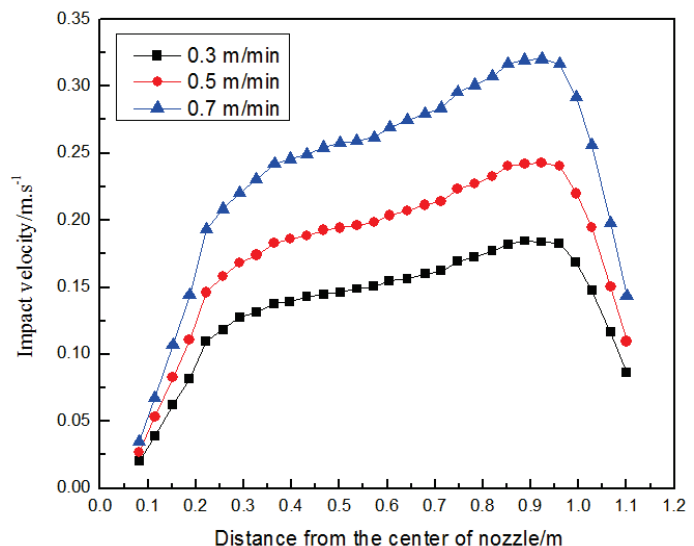

Figure 8 The velocity of flow is distributed along the width direction in the mould

Fig. 8 shows that the velocity of change is obvious at the same position with the increase of the casting speed. Compared with other casting speed, the liquid surface fluctuation is still small when the casting speed is 0.7 $\mathrm{m} / \mathrm{min}$, but by analysing the temperature field, the thickness of the shell has dropped to $18.7 \mathrm{~mm}$ in this 
condition, which is not enough to support the pressure of the liquid steel. Considering the results of the flow field and the temperature field, the casting speed should be kept at about $0.5 \mathrm{~m} / \mathrm{min}$.

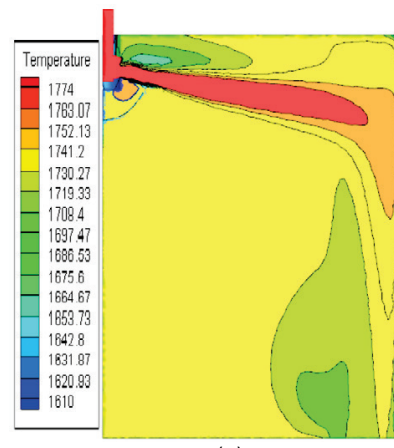

(a)

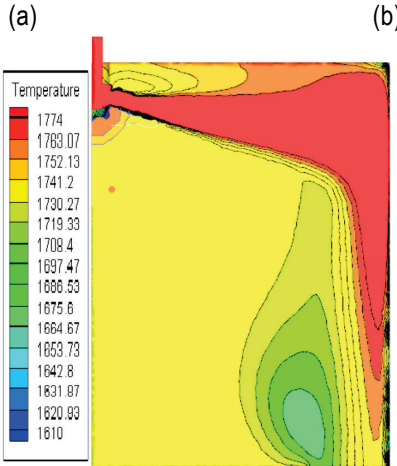

(c)

Figure 9 Distribution of wide surface temperature field at the different casting speed: (a) A casting speed of $0.3 \mathrm{~m} / \mathrm{min}$; (b) A casting speed of $0.5 \mathrm{~m} / \mathrm{min}$; (c) A casting speed of $0.7 \mathrm{~m} / \mathrm{min}$

The temperature field distribution in the mould at different casting speed, is shown in Fig. 9. It can be observed from the graph that the change of the casting speed has certain influence on the distribution of high temperature zone. Due to the casting speed increasing, it is increased for quantity and impact depth of the molten steel, and the high temperature area expands in continuous casting and moves downward slightly. The temperature was increased with increasing casting speed at the meniscus. At the same time, the centre temperature is raised in the whole continuous casting mould. So increasing the casting speed, the shell thickness at the mould outlet obviously becomes thinner. In continuous casting process, the solidification shell must have a certain thickness to resist the pressure and thermal stress from molten steel when continuous casting slab was pulled out of the mould, otherwise bulging deformation of the slab shell and breakout have happened in this procedure.

\section{CONCLUSION}

Flow behaviour of the special thick slab continuous casting mould of $400 \times 2200 \mathrm{~mm}$ was simulated. The values of the experimental and simulation results are in good agreement at positions A, B, and C. Meanwhile, the flow velocity of surface increases with the distance from the nozzle.

As the immersion depth of the nozzle was changed between $120 \mathrm{~mm}$ and $160 \mathrm{~mm}$, the impact position of the stream at the narrow surface changed from $0.04 \mathrm{~m}$ to 0.08 m. With the decrease of the immersion depth, the impact position of the stream rises and the upper recirculation zone is compressed while the lower recirculation zone shows a weakening tendency. Changing the immersion depth of the nozzle has less influence on the impacting velocity of the narrow surface. At the same time, with the immersion depth of the nozzle deepening, the maximum impacting velocity of narrow surface increases slightly. Therefore, the flow field and temperature field are reasonable in the mould when the immersion depth of the nozzle is $140 \mathrm{~mm}$.

When the casting speed is $0.3 \mathrm{~m} / \mathrm{min}$, the positions of the upper recirculation zone and lower recirculation zone were higher than $0.5 \mathrm{~m} / \mathrm{min}$ and $0.7 \mathrm{~m} / \mathrm{min}$. The impacting velocity of narrow surface was clearly enhanced in the mould when casting speed was increased from $0.3 \mathrm{~m} / \mathrm{min}$ to $0.7 \mathrm{~m} / \mathrm{min}$. The thickness of the solidification shell was reduced to $18.7 \mathrm{~mm}$ as the casting speed was $0.7 \mathrm{~m} / \mathrm{min}$ in the mould. At this time, the casting thickness cannot support the liquid steel pressure, so the casting speed is $0.5 \mathrm{~m} / \mathrm{min}$ and the flow field and temperature field are reasonable.

\section{Acknowledgments}

This research was financially supported by the National Natural Science Foundation of China (Grant No. 51474125, 51504130), Partial support was also provided by Foundation of Liaoning Educational Committee (2016HZPY05) and Special Fund of USTL (2017HZ01).

\section{REFERENCES}

[1] Lee, J. E., Yeo, T. J., Hwan OH, K. et al. (2000). Prediction of cracks in continuously cast steel beam blank through fully coupled analysis of fluid flow, heat transfer, and deformation behavior of a solidifying shell. Metallurgical and Materials Transactions A, 31(1), 225-237. https://doi.org/10.1007/s11661-000-0067-5

[2] Hwa-Soo, P. \& Yoon, J. K. (2001). Numerical Analysis of Fluid Flow and Heat Transfer in the Parallel Type Mold of a Thin Slab Caster. Transactions of the Iron and Steel Institute of Japan, 41(9), 974-980. https://doi.org/10.2355/isijinternational.41.974

[3] Xu, T., Zhang, L. H., Li, X. Q., et al. (2015). Numerical Simulation of Flow Field Coupling in Temperature Field of Tundish in Steady Magnetic Field. Special Casting and Nonferrous Alloys, 35(4), 365-369. https://doi.org/10.15980/j.tzzz.2015.04.009

[4] Mills, K. C., Ramirez-Lopez, P., Lee, P. D., et al. (2014). Looking into continuous casting mould. Ironmaking \& Steelmaking, 41(5), 242-249. https://doi.org/10.1179/0301923313Z.000000000255

[5] Thomas, B. G. \& Najjar, F. M. (2015). Finite element modelling of turbulent fluid flow and heat transfer in continuous casting. Applied Mathematical Modelling, 15(5), 226-243. https://doi.org/10.1016/0307-904X(91)90001-6

[6] Zhu, M. Y., Liu, J. Q., \& Xiao, Z, Q. (1996). Simulation of Molten Steel Flow in Slab Continuous Casting Mold. Iron and Steel, 31(8), 23-27. https://doi.org/10.13228/j.boyuan.issn0449-749x.1996.08.006

[7] Saraswat, R., Maijer, D. M., Lee, P. D., et al. (2007). The effect of mould flux properties on thermo-mechanical behaviour during billet continuous casting. ISIJ Int., 47(1), 95-104. https://doi.org/10.2355/isijinternational.47.95

[8] Anagnostopoulos, J. \& Bergeles, G. (1999). Three- 
dimensional modeling of the flow and the interface surface in a continuous casting mold model. Metall and Materials Trans B, 30(12), 1095-1105. https://doi.org/10.1007/s11663-999-0116-4

[9] López-Ramirez, S., Palafox-Ramos, J., Morales, R. D., et al. (2001). Modeling study of the influence of turbulence inhibitors on the molten steel flow, tracer dispersion, and inclusion trajectories in tundishes. Metallurgical and Materials Transactions B, 32(8), 615-627. https://doi.org/10.1007/s11663-001-0117-4

[10] Lin, X. C., Li, J. S., Zhang, X. L., et al. (2012). Water Model Experiments on Surface Flow Velocity of Molten Steel in Slab Caster Mold. China Metallurgy, 20(12), 1519. https://doi.org/10.13228/j.boyuan.issn1006-9356.2010.12.007

[11] Cheng, P. F., Tang, H. Y., Wu, G. H., et al. (2017). Surface flow velocity and flux behavior modelling in a billet continuous casting mold. Chinese Journal of Iron and Steel, 42(2), 1-6.

https://doi.org/10.13228/j.boyuan.issn1005-4006.20160119

\section{Contact information:}

\section{Bao YANG}

School of Materials and Metallurgy,

University of Science and Technology Liaoning,

Anshan 114051, P. R. China

E-mail: ybvip1991@163.com

Jing LI (Corresponding author)

School of Materials and Metallurgy,

University of Science and Technology Liaoning,

Anshan 114051, P. R. China

E-mail: lijing_as@163.com

\section{Lian-wang ZHANG}

School of Materials and Metallurgy,

University of Science and Technology Liaoning,

Anshan 114051, P. R. China

E-mail: Zhanglianwang92@163.com

\section{Yu ZHANG}

Zhongyuan Special Steel Co. Ltd,

Jiyuan, Henan 454650, P. R. China

E-mail: zhangyu15q@163.com

\section{$\mathrm{YeCUI}$}

Liaoning Fu-An Heavy Industry Co. Ltd,

Anshan 114051, P. R. China

E-mail: cuiyeq1@163.com

Chang-jun XU (Corresponding author)

School of Materials and Metallurgy,

University of Science and Technology Liaoning,

Anshan 114051, P. R. China

E-mail: jassonxu@ustl.edu.cn 